\title{
Halal Diets
}

\author{
Marco Tieman*
}

\section{Introduction}

Throughout the world, major shifts in dietary patterns are occurring, from carbohydrate-rich staples (cereals, roots, tubers) to vegetable oils, animal products (meat and dairy foods) to sugar. There is also an intake of increased energy supply from cheaper, processed food products. ${ }^{1}$ These new diets are a leading cause of cardiovascular disease, ${ }^{2}$ hypertension and stroke, ${ }^{3}$ obesity and type 2 diabetes, ${ }^{4}$ food allergies ${ }^{5}$ and some cancers. ${ }^{6}$ In order to prevent these diseases, research shows that vegetables and fruit should be the basis of our diets. ${ }^{7}$ However, our current food systems are providing us with high levels of salt, sugar and fat. ${ }^{8}$ Moreover, intensive meat and fish farming methods are using antibiotics in animal feed, both to prevent diseases in industrially raised animals and make those animals grow faster (therefore increasing feed efficiency). A side effect of this process is that these antibiotics also enter the human food chain. Various studies show that antibiotics significantly increase weight and body fat levels. The result of our current diets has been an increase in obesity, diabetes and associated diseases, reaching epidemic proportions in regions like Asia and the Middle East. ${ }^{9}$

Although the holy Quran prescribes equal importance to halal (lawful) and tayyib (wholesome: good and pure), the halal certification system today requires tayyib in the context of hygiene and food safety only, and not in the broader sense of wholesome (i.e. healthy, nutritious, sustainable, organic, etc.). As a result, the halal logo today cannot be blindly followed as an indicator of a healthy lifestyle choice for the consumer.

The halal certification of nutritionally deficient products is therefore misleading, as the holy Quran teaches us: 'Eat of what is on earth, lawful and good' (2:168). This situation allows manipulative marketing of halal products and sabotages effective government interventions, such as the introduction of sugar drink taxes or the banning of junk food advertising in Muslim countries. Healthy food options must become the easy choice for the consumer, which should be supported by the halal certification system.

The objective of this viewpoint paper is to understand the halal dietary laws and dietary recommendations from the holy Quran and Hadith and propose a halal certification system that better facilitates a healthy lifestyle choice for the consumer. 


\section{Dietary Guidelines from the Holy Quran and Hadith}

Allah encourages humans to conduct research into their food: "Then let men look at his food, (and how We provide it)" (80:24). Also, the Prophet (PBUH) frequently emphasised the importance of medicinal plants and various other foods. ${ }^{10}$ According to the holy Quran, an important basis of our diet is water, corn, olives, date-palms, grapes and every kind of fruit $(6: 99 ; 16: 10-11 ; 23: 19$; 80:24-32). Certainly, olives, date-palms and grapes have proven medicinal properties. ${ }^{11}$

The holy Quran also mentions the use of vegetable oil for food (23:20). The Prophet (PBUH) has said: 'Use the olive oil in your meals and also use it for massage. For this oil is obtained from a tree full of blessings' ${ }^{12}$ Current research shows that the use of (extra virgin) olive oil in our daily diet, also associated with the Mediterranean diet, has clear health benefits. ${ }^{13}$

Turning to Ramadan, this is a twenty-nine to thirty day fast in which food, fluids, medications, drugs and smoking are prohibited during the daylight hours, which can extend between thirteen and eighteen hours, depending on the geographical location and season. Scientific evidence shows the benefits of fasting for healthy aging. ${ }^{14}$

The holy Quran is clear on another point: "Eat and drink: but waste not by excess, for God loves not the wasters" (7:31). Therefore, reducing food waste is an important obligation to better feed the world. The current food supply chain, however, is characterised by high levels of waste in postharvest handling, storage, processing and packaging, distribution and consumption. Causes for high waste levels include poor storage facilities, poor logistics infrastructure and transportation, inadequate market facilities, poor packaging, high aesthetic standards for fruits and vegetables, poor temperature management, poor planning, short and confusing 'best-before-dates' (versus use-by-dates), and finally food leftover by the consumer. ${ }^{15}$

\section{Conclusion and Recommendation}

Despite more sophisticated medical technology and improved hygiene standards, we are going through an unprecedented epidemic of obesity and chronic dietrelated diseases, with no end in sight.

A healthy diet is based on a greater variety of unprocessed foods, particularly vegetables, fruits, olive oil, nuts, prebiotics, fibre and polyphenols. Bright coloured vegetables and fruits contain high levels of polyphenols. Selecting healthy foods on the basis of colour - counting 'colouries' rather than 'calories' - therefore makes sense. Also, the consumption of herbs can provide important medicinal benefits, with these plants having both disease preventing and curing attributes. 
Research shows that eating less meat is another important building block for a healthy diet, and one which will automatically reduce the intake of antibiotics from the industrial-scale antibiotic-dependent fish and meat industries.

Current halal logos are intended to provide insight solely into the compliance a product has with Shariah: is the food and its components lawful? Current halal logos do not integrate dietary requirements: is the food wholesome for you to eat? As noted, it can therefore be argued that the halal certification of nutritionally deficient products is misleading the consumer. Problems with our current food system make it clear that the Maqasid al-Shariah - in particular the protection of life and lineage - are not being sufficiently safeguarded by the current halal certification system. Therefore, a so-called traffic light system is proposed to integrate nutrient profiling into the halal logo. ${ }^{16}$

Under a traffic light system, the halal logo would have different colours: red, orange, or green. The colour would indicate if a product is a key building block of a healthy diet (green); a product with low levels of salt, sugar and/or fat (orange); or a product with high levels of salt, sugar, and/or fat (red). According to extensive research, the key building blocks of a healthy diet, or those things worthy of a 'green' certification, would include such products as plain oats, vegetables, fruits, beans, seeds, fish, white meats, healthy oils, water, tea, coffee, plant-based milk and yoghurts, sugar replacers, and very dark chocolates (beyond $70 \%$ cocoa). ${ }^{17}$ Foods with high levels of salt, sugar and fat, on the other hand, would earn 'red' certification, as these ingredients have been related to many of today's most serious diseases. ${ }^{18}$

Integrating nutrient profiling into the halal logo has a number of advantages. First of all, it makes it easier for the consumer to choose healthy food while shopping. Hence, the logo system could become an effective instrument in fighting the epidemic in obesity, diabetes and associated diseases. Secondly, government interventions, such as the introduction of sugar drink taxes or the banning of junk food advertising, can be more effectively implemented in Muslim countries which have a clear identification of nutritionally deficient products. Third, integrating nutrient profiling into the halal logo would motivate the food industry to innovate and offer healthier products.

Next to the clear advantages, however, there are also some disadvantages to integrating nutrient profiling into the halal logo. First, next to the possible costs of changing packaging, the fast food industry (which has a strong lobby) does not like their products being publicly branded as unhealthy, especially in the fastgrowing Muslim market. Much opposition from the fast food industry can thus be expected. A second disadvantage is that when a country introduces this new measure, it could be regarded as a non-tariff trade barrier by exporting countries, possibly affecting trade negotiations. 
Despite such disadvantages, however, the principles from the holy Quran and the Hadith, as well current medical dietary knowledge, suggest that incorporating nutrient profiling into the halal logo will eventually bring about health benefits and reduce healthcare costs. It will result in a more sustainable food system founded upon the actual sense of halal and tayyib.

\section{Notes}

* Dr. Marco Tieman is Adjunct Professor with Universiti Malaysia Pahang (Malaysia). He obtained his Master's degree in industrial engineering [logistics] from the University of Twente (the Netherlands) in 1997 and his PhD in business management [ halal supply chain management] from Universiti Teknologi MARA (Malaysia) in 2013. He is also the CEO of LBB International, an international logistics consultancy and research firm specialised in halal purchasing and supply chain management. He chaired the development of the international halal logistics standard (IHIAS, 0100:2010) under ICCI-IHI Alliance. Dr. Marco Tieman can be contacted at: marco@lbbinternational.com

1. Kearney, John. "Food Consumption Trends and Drivers." Philosophical Transactions of the Royal Society B: Biological Sciences 365.1554 (2010): 2793-2807.

2. Friel, Sharon, et al. "Public Health Benefits of Strategies to Reduce GreenhouseGas Emissions: Food and Agriculture." The Lancet 374.9706 (2009): 2016-2025.

3. World Health Organization. Diet, Nutrition and the Prevention of Chronic Diseases: Report of a Joint WHO/FAO Expert Consultation. Vol. 916. Diamond Pocket Books (P) Ltd., 2003.

4. Popkin, Barry M., Linda S. Adair, and Shu Wen Ng. "Global Nutrition Transition and the Pandemic of Obesity in Developing Countries." Nutrition reviews 70.1 (2012): 3-21. Bray, George A., and Barry M. Popkin. "Dietary Sugar and Body Weight: Have We Reached a Crisis in the Epidemic of Obesity and Diabetes? Health be Damned! Pour on the Sugar." Diabetes care 37.4 (2014): 950-956.

5. Branum, Amy M., and Susan L. Lukacs. "Food Allergy Among Children in the United States." Pediatrics 124.6 (2009): 1549-1555. Nowak-Węgrzyn, Anna, and Hugh A. Sampson. "Future Therapies for Food Allergies." Journal of Allergy and Clinical Immunology 127.3 (2011): 558-573. Sicherer, Scott H., and Hugh A. Sampson. "Food allergy." Journal of Allergy and Clinical Immunology 125.2 (2010): S116-S125.

6. Norat, Teresa, et al. "Fruits and Vegetables: Updating the Epidemiologic Evidence for the WCRF/AICR Lifestyle Recommendations for Cancer Prevention." Advances in Nutrition and Cancer. Springer Berlin Heidelberg, 2014: 35-50.

7. Boeing, Heiner, et al. "Critical review: vegetables and fruit in the prevention of chronic diseases." European Journal of Nutrition 51.6(2012): 637-663. Verburgh, Kris. The Food Hourglass: Slow Down the Ageing Process and Lose Weight. HarperCollins UK, 2014. Norat, Teresa, et al. "Fruits and Vegetables: Updating the Epidemiologic Evidence for the WCRF/AICR Lifestyle Recommendations for Cancer Prevention." Advances in Nutrition and Cancer. Springer Berlin Heidelberg, 2014. 35-50. 
8. Moss, Michael. Salt, Sugar, Fat: How the Food Giants Hooked Us. Random House, 2013. Bray, George A., and Barry M. Popkin. "Dietary sugar and body weight": have we reached a crisis in the epidemic of obesity and diabetes? Health be damned! Pour on the sugar." Diabetes care 37.4 (2014): 950-956.

9. Lam, David W., and Derek LeRoith. "The worldwide diabetes epidemic." Current Opinion in Endocrinology, Diabetes and Obesity 19.2 (2012): 93-96.

10. Islam, Md Sirajul, Sofiah Samsudin, and A. K. Azad. "Herbal Medicinal Importance of Citrullus Lanatus Mentioned in the Ahadith: A Precise Overview." American Journal of Ethnomedicine 2, no. 1 (2015): 2348-9502.

11. Saki, Kourosh, Behzad Kazemi-Ghoshchi, Jafar Asadzadeh, Aghakhan Kheiri, Ghader Hajigholizadeh, Abdosalam Sotoudeh, Mahmoud Rafieian-Kopaei, Fariba Bahmani, Vahid Bahmani, and Mahmoud Bahmani. "Quran medicine: studying from modern science perspective." J Nov Appl Sci 3, no. 1 (2014): 1298-1302.

12. Marwat, Sarfaraz Khan, Mir Ajab Khan, Muhammad Aslam Khan, M. Ahmad, M. Zafar, F. Rehman, and S. Sultana. "Fruit plant species mentioned in the Holy Qura'n and ahadith and their ethnomedicinal importance." American-Eurasian Journal of Agricultural and Environmental Science 5, no. 2 (2009): 284-295.

13. Verburgh, Kris. The Food Hourglass: Slow Down the Ageing Process and Lose Weight. HarperCollins UK, 2014. Tim Spector. "The Diet Myth: the real science behind what we eat". Weidenfeld \& Nicolson, London, 2015.

14. Anton, Stephen, and Christiaan Leeuwenburgh. "Fasting or Caloric Restriction for Healthy Aging." Experimental gerontology 48, no. 10 (2013): 1003-1005. Alkandari, Jasem Ramadan, Ronald J. Maughan, Rachida Roky, Abdul Rashid Aziz, and Umid Karli. "The implications of Ramadan fasting for human health and well-being." Journal of sports sciences 30, no. sup1 (2012): S9-S19.

15. Gustavsson, Jenny, Christel Cederberg, Ulf Sonesson, Robert Van Otterdijk, and Alexandre Meybeck. "Global food losses and food waste." Food and Agriculture Organization of the United Nations, Rome (2011).

16. Tieman, Marco and Faridah Hassan. Convergence of Food Systems. British Food Journal, Vol. 117, No. 9 (2015): pp 2313-2327.

17. Verburgh, Kris. The Food Hourglass: Slow Down the Ageing Process and Lose Weight. HarperCollins UK, 2014.

18. Moss, Michael. Salt, Sugar, Fat: How the Food Giants Hooked Us. Random House, 2013. 